\title{
Glycogen Synthase Kinase-3 $\beta$ Inhibitor Lithium Chloride Protects Against Inflammation-Mediated Skeletal Muscle Wasting
}

\section{Ji-Hyung Lee}

Gwangju Institute of Science and Technology

\section{Seon-Wook Kim}

Gwangju Institute of Science and Technology

Jun-Hyeong Kim

Gwangju Institute of Science and Technology

Hyung-Jun Kim

Gwangju Institute of Science and Technology

\section{Jungln Um}

Gwangju Institute of Science and Technology

\section{Da-Woon Jung}

Gwangju Institute of Science and Technology

\section{Darren Williams ( $\nabla$ darren@gist.ac.kr)}

Gwangju Institute of Science and Technology

\section{Research Article}

Keywords: cancer cachexia, intensive care unit acquired weakness, skeletal muscle wasting, lithium chloride, glycogen synthase kinase- $3 \beta$, sepsis

Posted Date: January 4th, 2021

DOl: https://doi.org/10.21203/rs.3.rs-133800/v1

License: (a) (1) This work is licensed under a Creative Commons Attribution 4.0 International License. Read Full License 


\section{Abstract}

Inflammation-mediated skeletal muscle wasting is induced by inflammatory cytokines. It occurs in critically ill patients with sepsis (termed intensive care unit acquired weakness) and patients with advanced metastasis (termed cancer cachexia). Both conditions severely impact on patient morbidity and mortality. Lithium chloride has been investigated as a drug repurposing candidate for numerous diseases. In this study, we assessed whether lithium chloride affects inflammation-mediated muscle wasting, using in vitro and in vivo models of cancer cachexia and sepsis. Lithium chloride prevented wasting in myotubes cultured with cancer cell conditioned media, maintained expression of the muscle fiber contractile protein, myosin heavy chain 2 and blocked upregulation of the E3 ubiquitin ligase, Atrogin-1. Glycogen synthase kinase-3 $\beta$ inhibition was indicated as the target mechanism, due to the following observations: 1) $\beta$-catenin was upregulated in the myotubes and 2) inhibition of IMPA1, the secondary biological target of lithium chloride, did not inhibit the effects of cancer conditioned media. Lithium chloride inhibited upregulation of the inflammation-associated cytokines II- $1 \beta$, II- 6 and inos in macrophages treated with lipopolysaccharide. Lithium chloride treatment in an animal model of sepsis improved body weight, increased muscle mass, preserved the survival of larger fibers and decreased expression of the wasting effector genes, Atrogin-1 and Murf-1. In a model of cancer cachexia, lithium chloride increased muscle mass, enhanced muscle strength and increased fiber cross sectional area, with no significant effect on tumorigenesis. These results indicate that lithium chloride could be repurposed as a drug to treat patients with inflammation-mediated skeletal muscle wasting.

\section{Introduction}

Inflammation-associated skeletal muscle wasting involves activation of the transcriptional complex NFKB (nuclear factor kappa-light-chain-enhancer of activated B cells) via increases in circulating cytokines, such as interleukin-1 $\beta$ (IL-1 $\beta)^{1}$. Examples include cancer cachexia and intensive care unit acquired weakness (ICUAW) produced by sepsis ${ }^{1-3}$. Both conditions result from acute-phase responses and systemic inflammation ${ }^{4,5}$. Cancer cachexia affects around $50 \%$ of all cancer patients and can be an immediate cause of death by increasing the side effects of chemotherapy ${ }^{6}$. ICUAW occurs in approximately $90 \%$ patients with severe sepsis and increases morbidity and mortality ${ }^{7}$. For patients with cancer cachexia, there are only limited treatment options and exercise programs are not always feasible, due to issues such as chronic fatigue and anemia ${ }^{8,9}$. ICUAW places a high financial burden on healthcare systems ${ }^{5,10}$. Therefore, the development of effective therapeutics for inflammation-associated muscle wasting is a research priority.

Lithium has been termed an "Oldie but Goodie" drug that was first used to treat psychiatric disorders in the nineteenth century ${ }^{11,12}$. It is a commonly prescribed treatment for bipolar disorder and is included in the World Health Organization's list of essential medicines ${ }^{13}$. Lithium chloride is also widely used in basic

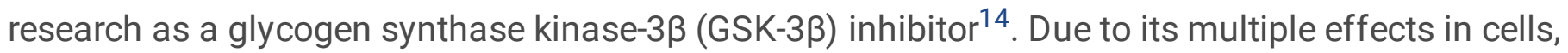


lithium has been studied as a drug repurposing candidate for numerous diseases, such as enterovirus infection, Parkinson's disease, radiation injury and rheumatoid arthritis ${ }^{15-18}$.

In this study, we investigated the effects of lithium chloride on inflammation-associated skeletal muscle wasting using in vitro and in vivo models of cancer cachexia and sepsis. Our results suggest that lithium chloride has potential for further development as a repurposing drug to treat inflammation-associated muscle wasting.

\section{Methods}

\section{Reagents}

Lipopolysaccharide (LPS) was purchased from Invitrogen, Thermo Fisher Scientific, Waltham, USA. Lithium chloride ( $\mathrm{LiCl}$ ) was purchased from Sigma-Aldrich, St. Louis, USA. Ebselen was purchased from Tokyo Chemical Industry, Japan. Antibodies for myosin heavy chain 2 (MyHC; catalogue number sc53095) and glyceraldehyde 3-phosphate dehydrogenase (GAPDH; catalogue number sc-365062) were purchased from Santa Cruz Biotechnology, Dallas, USA. A $\beta$-catenin antibody (catalogue number CST \#9562) was purchased from Cell Signaling Technology, Danvers, USA.

\section{Cell culture}

Cell culture was carried out as previously described ${ }^{19,20}$. C2C12 murine skeletal muscle precursor cells (myoblasts) were purchased from Koram Biotech Corp., Seoul, Republic of Korea, and maintained in growth media (GM), consisting of Dulbecco's Modified Eagle's Medium (DMEM) supplemented with 10\% fetal bovine serum (FBS), 50 units $/ \mathrm{mL}$ penicillin and $50 \mathrm{mg} / \mathrm{mL}$ streptomycin (PenStrep). Myoblasts were induced to differentiate into myotube by treatment with differentiation media (DM: DMEM supplemented with 2\% horse serum (HS) and PenStrep for 3 days). The RAW 264.7 murine macrophage and CT-26 murine colon carcinoma cell line were purchased from the Korean Cell Line Bank, Seoul, Republic of Korea, and cultured in GM.

\section{Collection of conditioned media}

To prepare cancer conditioned media (CCM), the previously described protocol was followed ${ }^{21}$. CT26 colon carcinoma cells were seeded in $100 \mathrm{~mm}$ culture plates at a density of $2 \times 10^{6}$ cells/plate. $48 \mathrm{~h}$ later, the culture media was changed to serum-free media. After 24 hours, the CCM were harvested, and debris was removed by centrifugation $\left(1,500 \mathrm{rpm}\right.$ for $3 \mathrm{~min}$ at $\left.4^{\circ} \mathrm{C}\right)$ and filtering with a $0.22 \mu \mathrm{m}$ disk filter (Corning, New York, USA).

\section{MTT assay for cell proliferation}

The 3-(4,5-dimethylthiazol-2-yl)-2,5-diphenyltetra -zolium bromide (MTT) assay was used for analyzing cell proliferation as previously described ${ }^{19,22}$. Myoblasts were seeded in a 96-well plate at a density of 
$1.5 \times 10^{3}$ cells per well. After 24 hours stabilization, compound of interest and/or CCM was applied for additional 48 hours. After, the medium was changed to MTT solution $(0.5 \mathrm{mg} / \mathrm{mL}$; final concentration), and incubated in a $37^{\circ} \mathrm{C}, 5 \% \mathrm{CO}_{2}$ incubator for 60 minutes. $50 \mu \mathrm{L}$ of DMSO was added to solubilize and optical density was measured at $570 \mathrm{~nm}$ using a microplate reader (VersaMax, Molecular Devices, San Jose, USA).

\section{Real-time quantitative PCR (qPCR)}

qPCR was carried out as previously described ${ }^{21}$. The RNAs were extracted by using TRizol reagent following manufacturer's instruction (Thermo Fisher Scientific, USA), and reverse transcribed with the AccuPower ${ }^{\circledR}$ RT PreMix (Bioneer, Daejeon, Republic of Korea). 2X Power SYBR® Green PCR Master Mix (Applied Biosystems, UK) was used for real-time PCR with specific primers. For amplification and detection, StepOnePlus Real Time PCR System (Applied Biosystems, UK) was used according to the manufacturer's instructions. The expression level of Gapdh was used for normalization while calculating the expression levels of all of the other genes (as indicated in the text). Primer details are shown in Table 1.

Table 1: qPCR primers used in this study 


\begin{tabular}{|c|c|c|c|c|c|}
\hline Gene & Locus & Source & & Primer sequence & Size \\
\hline \multirow{2}{*}{$\begin{array}{l}\text { Myosin heavy } \\
\text { chain } 2(\text { Myh2) }\end{array}$} & \multirow[t]{2}{*}{ NM_001039545 } & \multirow{2}{*}{$\begin{array}{l}\text { Mus } \\
\text { musculus }\end{array}$} & Forward & GAAGAGCCGGGAGGTTCAC & \multirow{2}{*}{$\begin{array}{l}113 \\
\mathrm{bp}\end{array}$} \\
\hline & & & Reverse & ACACAGGCGCATGACCAAA & \\
\hline \multirow[t]{2}{*}{ Pax-7 } & \multirow[t]{2}{*}{ NM_011039 } & \multirow{2}{*}{$\begin{array}{l}\text { Mus } \\
\text { musculus }\end{array}$} & Forward & СССTTTCAAAGACCAAATGCA & \multirow{2}{*}{$\begin{array}{l}198 \\
\mathrm{bp}\end{array}$} \\
\hline & & & Reverse & ССCTCACGGGCAGATCATTA & \\
\hline \multirow[t]{2}{*}{ Atrogin-1 } & \multirow[t]{2}{*}{ NM_026346 } & \multirow{2}{*}{$\begin{array}{l}\text { Mus } \\
\text { musculus }\end{array}$} & Forward & CAGAGAGCTGCTCCGTCTCA & \multirow{2}{*}{$\begin{array}{l}178 \\
\mathrm{bp}\end{array}$} \\
\hline & & & Reverse & ACGTATCCCCCGCAGTTTC & \\
\hline \multirow[t]{2}{*}{ MuRF-1 } & \multirow[t]{2}{*}{ NM_001039048 } & \multirow{2}{*}{$\begin{array}{l}\text { Mus } \\
\text { musculus }\end{array}$} & Forward & CCGAGTGCAGACGATCATCTC & \multirow{2}{*}{$\begin{array}{l}198 \\
\text { bp }\end{array}$} \\
\hline & & & Reverse & TGGAGGATCAGAGCCTCGAT & \\
\hline \multirow[t]{2}{*}{$\| 1-6$} & \multirow[t]{2}{*}{ NM_031168 } & \multirow{2}{*}{$\begin{array}{l}\text { Mus } \\
\text { musculus }\end{array}$} & Forward & GAGGATACCACTCCCAAC & \multirow{2}{*}{$\begin{array}{l}141 \\
\mathrm{bp}\end{array}$} \\
\hline & & & Reverse & AAGTGCATCATCGTTGTT & \\
\hline \multirow[t]{2}{*}{ inos } & \multirow[t]{2}{*}{ NM_010927 } & \multirow{2}{*}{$\begin{array}{l}\text { Mus } \\
\text { musculus }\end{array}$} & Forward & ССССTTCAATGGCTGGTACA & \multirow{2}{*}{$\begin{array}{l}64 \\
\mathrm{bp}\end{array}$} \\
\hline & & & Reverse & GCGCTGGACGTCACAGAA & \\
\hline \multirow[t]{2}{*}{$\|-1 \beta$} & \multirow[t]{2}{*}{ NM_008361 } & \multirow{2}{*}{$\begin{array}{l}\text { Mus } \\
\text { musculus }\end{array}$} & Forward & TGCCACCTTTTGACAGTGATG & \multirow{2}{*}{$\begin{array}{l}135 \\
\mathrm{bp}\end{array}$} \\
\hline & & & Reverse & TGTGCTGCTGCGAGATTTGA & \\
\hline \multirow[t]{2}{*}{ Gapdh } & \multirow[t]{2}{*}{ NM_001289726 } & \multirow{2}{*}{$\begin{array}{l}\text { Mus } \\
\text { musculus }\end{array}$} & Forward & СТCCACTCACGGCAAATTCA & \multirow{2}{*}{$\begin{array}{l}120 \\
\mathrm{bp}\end{array}$} \\
\hline & & & Reverse & GCCTCACCCCATTTGATGTT & \\
\hline
\end{tabular}

\section{In vitro model of cancer cachexia and morphological analysis of myotubes.}

An in vitro model of cancer cachexia was established using the previously published protocol ${ }^{23} \cdot 3 \times 10^{5}$ myoblasts were seeded in each well of a 12 well plate and stabilized for $24 \mathrm{~h}$ in GM. The media was changed into DM for $72 \mathrm{~h}$ to produce myotube. Myotubes were treated with 1:1 ratio of DM and CCM for 72 hours to induce myotube wasting. Compounds of interest were added into CCM mixture before administration. Myotubes were then fixed with $4 \%$ formaldehyde and permeabilized with PBS containing 0.5\% Triton X-100 (Sigma Aldrich, USA). Myosin Heavy chain 2 (MyHC) antibody (Santa Cruz, USA) was treated in $1 \%$ BSA in PBST $\left(0.02 \%\right.$ Tween 20 in PBS) for overnight at $4^{\circ} \mathrm{C}$. The secondary antibody, Alexa fluor 488(ThermoFisher, USA), was applied for 1 hours at room temperature. Fluorescence images were taken in 5 different area by using DMI 3000 B(Leica, Germany) and analyzed with ImageJ 1.52 software (National institutes of Health, Bethesda, MD, USA). MyHC positive myotube containing more than 3 nuclei were considered as myotube and measured diameter.

\section{Immunoblotting}


Immunoblotting was performed as previously described ${ }^{21}$. Briefly, the concentration of protein lysate was quantified using the Bradford reagent (Bio-Rad, Hercules, USA,). After electrophoresis, separated proteins were transferred on to PVDF membranes, blocked with $5 \%$ non-fat powdered milk in TBST $(0.02 \%$ Tween 20 in TBS), and subsequently incubated overnight at $4^{\circ} \mathrm{C}$ with the primary antibody. The secondary antibody was used at a 1: 10000 dilution (For mouse: Abcam, cat. no. ab6789, For rabbit : Cell Signaling Technology, cat. No. \#7004). Detection was performed with ImageQuant ${ }^{\text {TM }}$ LAS 500(GE Healthcare, USA) with manufacturer's instruction, quantified by using ImageJ 1.52 software (National Institutes of Health). Full-length blots are included as Supplementary Information Figure 1 and 2.

\section{Assessment of pro-cachexia cytokine induction in macrophages}

RAW 264.7 macrophages were seeded in 6 well culture plates at a density of $5 \times 10^{5}$ cells/well. $24 \mathrm{~h}$ later, macrophages were pre-treated with compound of interest for $1 \mathrm{~h}$, followed by $200 \mathrm{ng} / \mathrm{mL}$ LPS and compound for $24 \mathrm{~h}$. RNA was then isolated using the Trizol reagent and cytokine gene expression measured using qPCR, as described above.

\section{Animal studies}

Animal experiments were carried out in accordance with the ethical guidelines established by the Animal Care and Use Committee of the Gwangju Institute of Science and Technology, Republic of Korea (study approval number: GIST-2019-042). The experimental protocols were approved by the Animal Care and Use Committee of the Gwangju Institute of Science and Technology, Republic of Korea. In addition to the guidelines established by the ACUC, the study was carried out in compliance with the ARRIVE guidelines. Animals were supplied by Damool Science, Republic of Korea.

\section{Animal model of sepsis-induced muscle wasting}

Studies of the therapeutic effect of $\mathrm{LiCl}$ on sepsis-induced muscle wasting in vivo were based on the previously published protocols ${ }^{24,25}$. 10 weeks old male C57BL/ 6 mice were randomly assigned into the following treatment groups: 1) $4 \mathrm{~d}$ intraperitoneal (IP) injection of saline vehicle every $24 \mathrm{~h}, 2) 4 \mathrm{~d}$ IP delivery of $40 \mathrm{mg} / \mathrm{kg} \mathrm{LiCl}$ every $24 \mathrm{~h}, 3$ ) Untreated. On the fourth day, $1 \mathrm{mg} / \mathrm{kg}$ LPS was treated to the saline and $\mathrm{LiCl}$ groups by IP, and the untreated group received saline by IP. $18 \mathrm{~h}$ after LPS injection, mice were anaesthetized using ketamine (22 mg/kg; Yuhan, Republic of Korea) and xylazine (10 mg/kg; Bayer, Republic of Korea) and sacrificed. Mouse limb muscles were dissected, weighed and frozen at $-80{ }^{\circ} \mathrm{C}$.

\section{Animal model of cancer cachexia model}

The murine model of cancer cachexia was based on a previous study ${ }^{23} .10$ weeks old male BALB/c mice were randomly assigned into the following treatment groups: 1) $1 \times 10^{6}$ of CT26 colon cancer cells inoculated subcutaneously (SC) in the right flank, 2) Equal volume of saline inoculated SC in the right flank. Tumor growth was monitored twice weekly, and tumor volume was calculated using a caliper and 
administration of $\mathrm{LiCl}$ was conducted with specific concentration for $21 \mathrm{~d}$. Grip strength was measured using the BIO-GS3 strength meter (Bioseb, France). Each mouse was tested 4 times with a $30 \mathrm{sec}$ interval and the maximum value force was used to represent muscle force. $28 \mathrm{~d}$ after CT26 cell or saline injection, mice were anaesthetized and sacrificed for further analysis.

\section{Histological analysis}

Histological analysis of dissected muscles was carried out as previously described ${ }^{26}$. Quadriceps were fixed with $4 \%$ paraformaldehyde solution overnight at $4{ }^{\circ} \mathrm{C}$ and embedded into paraffin. $5 \mu \mathrm{m}$ of each muscle sections were made stained with hematoxylin and eosin (H\&E) using a kit (Merck, Darmstadt, Germany). Images were obtained by light microscopy (Leica, DM 2500) and cross sectional areas were measured by Image J 1.52 software (National Institute of Health).

\section{Statistics}

Microsoft Excel 2016 (Redmond, USA) was used to determine statistical significance with the Student's $t$ test in Figures 1-4. ANOVA test was used to determine statistical significance in Figures 5-7 (Tukey's posthoc comparison of the means using Origin Pro 9.1 software). $p$ values of less than 0.05 were deemed to be statistically significant. Unless otherwise stated in the figure legends, experiments were carried out in triplicate and the error bars are standard deviation.

\section{Results}

\section{$\mathrm{LiCl}$ increases Myh2 expression and reduces Pax-7 expression in differentiating myoblasts treated with CCM}

$\mathrm{LiCl}$ has been reported to induce myogenic differentiation in $\mathrm{C} 2 \mathrm{C} 12$ myoblasts ${ }^{27,28}$. Prior to evaluate the effect on cancer cachexia, we verified the phenotype of $\mathrm{LiCl}$ on myogenic differentiation. As expected, treatment of $\mathrm{LiCl}$ reduced the expression of paired box protein Pax-7 (a myoblast marker indicating myotube dedifferentiation ${ }^{46,47}$ ) while increasing the expression Myh2 (a myotube marker ${ }^{2}$ ) (Figure 1A-B). $\mathrm{CCM}$ has been shown to contain factors that inhibit both myoblast proliferation and myogenic differentiation ${ }^{29}$. To test the effect of $\mathrm{LiCl}$ on proliferation and differentiation, $\mathrm{C} 2 \mathrm{C} 12$ myoblasts were treated with $\mathrm{CCM}$, or CCM containing $\mathrm{LiCl}$. CM treatment significantly reduced $\mathrm{C} 2 \mathrm{C} 12$ myoblast proliferation. $\mathrm{LiCl}$ did not affect this inhibition of myoblast proliferation (Figure 1C-D). To investigate the effect $\mathrm{LiCl}$ on myogenic differentiation in the presence of $\mathrm{CCM}$, the expression of Pax-7 and Myh2 was measured in differentiating myoblasts treated with CCM or CCM plus LiCl. CCM increased the expression of Pax-7 and decreased the expression of Myh2. LiCl inhibited the effect of CCM on Pax-7 and Myh2 expression (Figure 1E-F).

\section{LiCl prevents CCM-induced myotube wasting}


Differentiated $\mathrm{C} 2 \mathrm{C} 12$ myotubes were treated with CCM with or without LiCl. CCM treated myotubes showed an almost $30 \%$ decrease in diameter, which was prevented by co-treatment with $\mathrm{LiCl}$ (Figure 2AB). Measurement of myotube diameter distribution indicated that $\mathrm{LiCl}$ preserved larger sized myotubes (Figure 2C). Similar to differentiating myoblasts, $\mathrm{LiCl}$ prevented both the upregulation of Pax-7 and downregulation of $\mathrm{MyHC}$ in the myotubes (Figure 2D-E). $\mathrm{LiCl}$ is known to function as a GSK-3 $\beta$ inhibitor that upregulates the expression of $\beta$-catenin ${ }^{30}$. LiCl treated myotubes increased expression of $\beta$-catenin in the presence of CCM (Figure 2F). The E3 ubiquitin ligase, atrogin-1 (MAFbx/ FBXO32) is a major effector of the increased muscle proteolysis in cancer cachexia ${ }^{31,32}$. Atrogin-1 expression was upregulated in myotubes treated with CCM myotubes and inhibited by treatment with $\mathrm{LiCl}$ (Figure 2D).

\section{Lithium mimetic ebselen does not prevent myotube wasting induced by CCM}

The synthetic organoselenium drug, ebselen, has been reported as a lithium mimetic by inhibiting the secondary lithium target, IMPase ${ }^{33}$. We investigated if the effects of lithium on CCM-treated myotubes can be reproduced by ebselen. It was observed that ebselen did not attenuate the reduction of myotube diameter after CCM treatment (Figure 3A-B). In addition, ebselen did not inhibit the upregulation of Atrogin-1 and Pax-7expression, or the downregulation of Myh2, by CCM (Figure 3C-D).

\section{LiCl inhibits LPS-induced inflammatory cytokine production}

Measuring the induction of inflammatory cytokines in macrophages treated with LPS has been used as a model for sepsis ${ }^{34}$. RAW264.7 macrophages were treated with LPS in the presence or absence of LiCl, and induction of the cachexia-related cytokines $11-1 b^{35}, 11-6^{36}$ and $i n o s^{37}$ was measured by qPCR. It was observed that $\mathrm{LiCl}$ treatment significantly reduced the induction of $I I-1 \beta$, II-6 and inos by LPS (Figure 4).

\section{$\mathrm{LiCl}$ prevents muscle wasting in a mouse model of septic cachexia}

In order to investigate the protective effect of $\mathrm{LiCl}$ on inflammation-induced muscle wasting, we first employed a mouse model of septic cachexia using LPS ${ }^{25} .18 \mathrm{~h}$ post-LPS injection, there was significant reduction in body weight compared to mice with saline treatment. Administration of $\mathrm{LiCl}$ attenuated this decline in body weight (Figure 5A). Quadriceps muscle weight was measured to determine the effect of $\mathrm{LiCl}$ on muscle wasting. LPS treatment decreased muscle mass and $\mathrm{LiCl}$ treatment attenuated muscle loss (Figure 5B). The effect of $\mathrm{LiCl}$ on sepsis-induced fiber wasting was assessed by measuring cross sectional area in the quadriceps. LPS produced a significant reduction in muscle fiber CSA, which was ameliorated by $\mathrm{LiCl}$ treatment (Figure 5C-D). Additionally, the proportion of relatively large fibers was maintained in the LiCl group (Figure 5E). Skeletal muscle E3 ligases are known to mediate LPS induced muscle wasting ${ }^{25}$. As expected, LPS treatment upregulated the expression of the E3 ligases, Atrogin-1 and Murf-1. LiCl inhibited the induction of atrogin-1 and MuRF-1 (Figure 5F). Since inos is known to be an important regulator of cytokine-mediated muscle wasting ${ }^{38,39}$, the expression of this gene was also measured. LiCl completely inhibited the induction of inos gene after LPS administration (Figure 5F). 
To further validate the anti-atrophic effect of $\mathrm{LiCl}$ on inflammation induced muscle wasting, we used a syngeneic mouse model of cancer cachexia based on the transplantation of CT26 colon carcinoma cells into BALB/c mice, as previously described ${ }^{40}$. Treatment with $\mathrm{LiCl}$ did not significantly affect the overall body weight of CT26 tumor bearing mouse (Figure 6A and D). In addition, tumor growth was not altered by $\mathrm{LiCl}$ (Figure 6B-C). Skeletal muscle and adipose tissue are among the most affected tissues in cancer cachexia ${ }^{41}$. Tumor bearing mice showed a significant reduction in quadriceps muscle, tibialis anterior muscle and gonadal adipose tissue weight. LiCl treatment significantly ameliorated quadriceps and tibialis anterior muscle loss (Figure 6E). In contrast, adipose tissue mass was not affected by LiCl (Figure 6F). Grip strength was measured to assess whether the improvement in muscle mass after LiCl treatment influenced muscle function. $\mathrm{LiCl}$ increased muscle function at the $80 \mathrm{mg} / \mathrm{kg}$ treatment dose (Figure 6G). In line with the grip strength data, the $80 \mathrm{mg} / \mathrm{kg}$ dose preserved average fiber cross sectional area, with a higher proportion of fibers in the $4000-5000 \mu \mathrm{m}^{2}$ range (Figure $6 \mathrm{H}-\mathrm{I}$ ). The increased expression of Atrogin1 and Murf- 1 in tumor bearing mice was attenuated in both the 40 and $80 \mathrm{mg} / \mathrm{kg} \mathrm{LiCl} \mathrm{treatment} \mathrm{groups}$ (Figure 7A). In addition to E3 ligases, previous studies have demonstrated the role of interleukin-6 on the progression of cancer mediated muscle wasting ${ }^{42,43}$. Significant upregulation of II- 6 was observed in the skeletal muscle tissue in tumor bearing mice, and administration of $\mathrm{LiCl}$ completely inhibited the tumorinduced increase of II-6 (Figure 7A).

\section{Discussion}

Inflammation-associated skeletal muscle wasting is produced by cytokines, such as IL-1 $\beta$ and IL-6. It occurs in cancer cachexia and ICUAW and significantly affects patient morbidity and mortality. Due to a lack of effective treatment options, this study investigated the potential of $\mathrm{LiCl}$ to treat these disorders. It was observed that $\mathrm{LiCl}$ was effective at inhibiting wasting in cell-based and animal models of inflammation-mediated skeletal muscle wasting.

$\mathrm{LiCl}$ treatment was shown to upregulate $\beta$-catenin expression in myotubes incubated with CCM. $\beta$-catenin protein levels are known to be down-regulated in muscle wasting and activation of the Wnt signaling pathway by GSK-3 $\beta$ inhibition increases $\beta$-catenin expression ${ }^{44}$. In addition, therapy with the Wnt family member, Wnt7a, has been shown to increase $\beta$-catenin levels and inhibit cancer cachexia ${ }^{45}$. These findings indicate that GSK-3 $\beta$ inhibition by $\mathrm{LiCl}$ could be the mechanism by which this compound prevents cancer cachexia. This is also supported by our data showing that targeting the secondary biological target of LiCl, IMPase, using the chemical inhibitor, ebselen, did not prevent CCM-induced myotube wasting in vitro 33,46 . There are numerous reports of role of GSK-3 $\beta$ inhibition in myotube differentiation and atrophy in vivo and in vitro ${ }^{47-50}$. We believe that the significance of our study is the demonstration that a clinically approved GSK-3 $\beta$ inhibitor ( $\mathrm{LiCl}$ ) can prevent inflammation mediated myotube atrophy in animal models. The small molecule GSK-3 $\beta$ inhibitor, 6-bromoindirubin-3'-oxime (BIO) has been reported to enhance skeletal muscle regeneration in vivo ${ }^{51}$. However, BIO not yet approved for clinical use and is known to inhibit JAK/STAT3 signaling, which can also enhance muscle regeneration 
The animal studies revealed a difference in the LiCl dosage required for effectiveness in LPS-induced muscle wasting and cancer cachexia. The $40 \mathrm{mg} / \mathrm{kg}$ dose was effective in the LPS model, while 80 $\mathrm{mg} / \mathrm{kg}$ was needed for effectiveness in the cancer cachexia model. This may be due to differences in the treatment regime between the two models. In the cancer cachexia model, $\mathrm{LiCl}$ was treated $10 \mathrm{~d}$ after the transplantation of cancer cells. At this time point the inflammatory environment is already established. Thus, a higher dosage of $\mathrm{LiCl}$ may be needed to inhibit the progression of wasting in this model.

$\mathrm{LiCl}$ was effective at preserving muscle mass and function in tumor bearing mice. However, gonadal adipose was unaffected by LiCl treatment. GSK-3 $\beta$ activity is known to increase in animal models with greater adiposity ${ }^{54}$. In addition, repressing Wnt signaling has been shown to enhance adipogenesis ${ }^{55}$. Therefore, LiCl-mediated GSK-3 $\beta$ inhibition and increased Wnt signaling may explain the lack of effect on adipose tissue mass. It should also be noted that skeletal muscle wasting rather than adipose tissue wasting is used in the formal definition of cancer cachexia ${ }^{56}$. Thus, treatments for cancer cachexia should ideally target skeletal muscle mass rather than adipose tissue.

It was previously reported that lithium carbonate $\left(\mathrm{Li}_{2} \mathrm{CO}_{3}\right)$ therapy was ineffective at treating cancer cachexia ${ }^{57}$. These different results compared to the current study could be explained by the models used to assess cancer cachexia. The $\mathrm{Li}_{2} \mathrm{CO}_{3}$ study utilized a model of hepatoma. However, unlike colon carcinoma, hepatoma is not commonly associated with cancer cachexia ${ }^{56}$. In addition, there was no in vitro demonstration of myotube wasting after treatment with hepatoma $\mathrm{CCM}$ or its prevention by $\mathrm{Li}_{2} \mathrm{CO}_{3}$.

Lithium has been previously investigated as a treatment for sepsis-induced myotube wasting ${ }^{58}$. It was concluded that $\mathrm{LiCl}$ may be partially effective at preventing sepsis-induced muscle wasting. However, this previous study was carried out in a different animal model (Sprague-Dawley rats) and only reported ex vivo data, in which dissected muscles from septic animals were incubated with LiCl-supplemented buffer. Our results build upon this report by demonstrating that direct treatment with $\mathrm{LiCl}$ can prevent sepsisinduced muscle wasting in vivo.

Lithium has been used as a neuroprotective agent in patients with cancer ${ }^{59}$. Protective effects of lithium on motor neurons may contribute to the reduced muscle wasting observed in the current study. Our in vitro data indicated that $\mathrm{LiCl}$ also has a direct effect on preventing muscle wasting, because treated myotubes showed reduced wasting and lower expression of atrogin-1 in the presence of CCM.

The in vitro and in vivo experiments in this study utilized the CT26 colon carcinoma cell line, because cancer cachexia is commonly associated with this tumor type ${ }^{60}$. Cancer cachexia is also a common complication of lung, breast and pancreatic carcinoma ${ }^{61}$. As a future study, it may be interesting to test the effectiveness of $\mathrm{LiCl}$ to treat cachexia in models of these tumor types.

It is interesting to note that the effect of $\mathrm{LiCl}$ was rapid in this study ( $96 \mathrm{~h}$ treatment for the sepsis model). In contrast, lithium takes longer to become effective in bipolar patients, usually around 6-8 weeks ${ }^{11}$. 
indicated the need to re-evaluate the effect of lithium on kidney function, due to reports of protective outcomes in models of acute and chronic kidney disease ${ }^{62}$. Although Wnt pathway activation is associated with cancer progression, it has been shown that long term lithium therapy does not increase cancer risk ${ }^{63}$. Moreover, the potentially beneficial effects of lithium therapy was revealed in analyses showing enhanced life expectancy in humans and metazoans ${ }^{64}$. These reports support the potential development of lithium therapy for patients with muscle wasting.

In summary, the results presented herein show that LiCl treatment is effective in two models of skeletal muscle wasting: cancer cachexia produced by tumor-derived factors, and endotoxin-induced muscle weakness resulting from sepsis. A two-fold higher dose was required for effectiveness in the cancer cachexia model compared to the sepsis model. Further studies could assess the potential of LiCl treatment in other types of skeletal muscle wasting, such as aging-related sarcopenia, sarcopenic obesity and immobilization-induced muscle wasting.

\section{Declarations}

\section{Acknowledgements}

This work was supported by the National Research Foundation of Korea (NRF) funded by the Korean government (MSIT) (No.2020R1A2C2014194) and the Bio \& Medical Technology Development Program of the National Research Foundation (NRF) funded by the Korean government (MSIT) (No. NRF2020M3A9G3080282). This work was partly supported by the Institute for Information and Communications Technology Promotion (IITP) grant funded by the Korea government (MSIP; No. 2019-000567, Development of Intelligent SW systems for uncovering genetic variation and developing personalized medicine for cancer patients with unknown molecular genetic mechanisms). This work was supported by "GIST Research Institute (GRI) ARI" grant funded by the GIST in 2020.

\section{Author contributions}

$\mathrm{J}-\mathrm{H}$ Lee designed experiments and carried out the cell-based and animal model experiments, S-W K, H-J Kim and $\mathrm{J} U$ contributed to the animal model experiments, J-H Kim carried out cell-based experiments, D$\mathrm{W} \mathrm{J}$ and $\mathrm{D}-\mathrm{R} \mathrm{W}$ designed experiments and wrote/edited the manuscript.

\section{Conflict of interest}

The authors declare no conflict of interest in relation to this study.

\section{References}

1 Mourkioti, F. \& Rosenthal, N. NF-kappaB signaling in skeletal muscle: prospects for intervention in muscle diseases. J Mol Med (Berl)86, 747-759, doi:10.1007/s00109-008-0308-4 (2008). 
2 Zhang, G. et al. Tumor induces muscle wasting in mice through releasing extracellular Hsp70 and Hsp90. Nat Commun8, 589, doi:10.1038/s41467-017-00726-x (2017).

3 Hadi, A. M. et al. Rapid quantification of myocardial fibrosis: A new macro-based automated analysis. Analytical cellular pathology33, 257-269, doi:10.3233/ACP-CLO-2010-0548 (2010).

4 Stephens, N. A., Skipworth, R. J. \& Fearon, K. C. Cachexia, survival and the acute phase response. Curr Opin Support Palliat Care2, 267-274, doi:10.1097/SPC.0b013e3283186be2 (2008).

5 Hahn, A. et al. Serum amyloid A1 mediates myotube atrophy via Toll-like receptors. Journal of cachexia, sarcopenia and muscle11, 103-119, doi:10.1002/jcsm.12491 (2020).

6 Alhamarneh, O., Agada, F., Madden, L., Stafford, N. \& Greenman, J. Serum IL10 and circulating CD4(+) CD25(high) regulatory $\mathrm{T}$ cell numbers as predictors of clinical outcome and survival in patients with head and neck squamous cell carcinoma. Head \& neck33, 415-423, doi:10.1002/hed.21464 (2011).

7 Ali, N. A. et al. Acquired weakness, handgrip strength, and mortality in critically ill patients. American journal of respiratory and critical care medicine178, 261-268, doi:10.1164/rccm.200712-18290C (2008).

8 Penet, M. F. \& Bhujwalla, Z. M. Cancer cachexia, recent advances, and future directions. Cancer journa/21, 117-122, doi:10.1097/PP0.0000000000000100 (2015).

9 Argiles, J. M., Busquets, S., Lopez-Soriano, F. J., Costelli, P. \& Penna, F. Are there any benefits of exercise training in cancer cachexia? Journal of cachexia, sarcopenia and muscle3, 73-76, doi:10.1007/s13539012-0067-5 (2012).

10 De Jonghe, B. et al. Paresis acquired in the intensive care unit: a prospective multicenter study. Jama288, 2859-2867, doi:10.1001/jama.288.22.2859 (2002).

11 Won, E. \& Kim, Y. K. An Oldie but Goodie: Lithium in the Treatment of Bipolar Disorder through Neuroprotective and Neurotrophic Mechanisms. Int J Mol Sci18, doi:10.3390/ijms18122679 (2017).

12 Shorter, E. The history of lithium therapy. Bipolar Disord11 Suppl 2, 4-9, doi:10.1111/j.13995618.2009.00706.x (2009).

13 McKnight, R. F. et al. Lithium for acute mania. The Cochrane database of systematic reviews6, CD004048, doi:10.1002/14651858.CD004048.pub4 (2019).

$14 \mathrm{Xu}, \mathrm{M}$. et al. Structure-activity relationship (SAR) studies of synthetic glycogen synthase kinase-3beta inhibitors: A critical review. Eur J Med Chem164, 448-470, doi:10.1016/j.ejmech.2018.12.073 (2019).

15 Hung, H. C., Shih, S. R., Chang, T. Y., Fang, M. Y. \& Hsu, J. T. The combination effects of licl and the active leflunomide metabolite, A771726, on viral-induced interleukin 6 production and EV-A71 replication. Plnsonea e111231 doi-10 1271/inurnal nnne.0111331 (2014).

Loading [MathJax]/jax/output/CommonHTML/jax.js

Page $12 / 22$ 
16 Thompson, C. L. et al. Lithium chloride prevents interleukin-1beta induced cartilage degradation and loss of mechanical properties. J Orthop Res33, 1552-1559, doi:10.1002/jor.22913 (2015).

17 Guttuso, T., Jr. High lithium levels in tobacco may account for reduced incidences of both Parkinson's disease and melanoma in smokers through enhanced beta-catenin-mediated activity. Med Hypotheses131, 109302, doi:10.1016/j.mehy.2019.109302 (2019).

18 Verma, Y. K., Singh, A. K. \& Gurudutta, G. U. Survival genes expression analysis following ionizing radiation to LiCl treated KG1a cells. Int J Radiat Biol, 1-18, doi:10.1080/09553002.2020.1721592 (2020).

$19 \mathrm{Kim}, \mathrm{A}$. R. et al. Screening ginseng saponins in progenitor cells identifies 20(R)-ginsenoside Rh2 as an enhancer of skeletal and cardiac muscle regeneration. Scientific reports 10,4967 , doi:10.1038/s41598020-61491-4 (2020).

$20 \mathrm{Kim}, \mathrm{Y}$. S. et al. Natural product derivative BIO promotes recovery after myocardial infarction via unique modulation of the cardiac microenvironment. Scientific reports6, 30726, doi:10.1038/srep30726 (2016).

$21 \mathrm{Cho}, \mathrm{H}$. et al. Cancer-Stimulated CAFs Enhance Monocyte Differentiation and Protumoral TAM Activation via IL6 and GM-CSF Secretion. Clinical cancer research : an official journal of the American Association for Cancer Research, doi:10.1158/1078-0432.CCR-18-0125 (2018).

22 Mosmann, T. Rapid colorimetric assay for cellular growth and survival: application to proliferation and cytotoxicity assays. Journal of immunological methods65, 55-63 (1983).

23 Chen, X. et al. Salidroside alleviates cachexia symptoms in mouse models of cancer cachexia via activating mTOR signalling. Journal of cachexia, sarcopenia and muscle7, 225-232, doi:10.1002/jcsm.12054 (2016).

24 Jin, B. \& Li, Y. P. Curcumin prevents lipopolysaccharide-induced atrogin-1/MAFbx upregulation and muscle mass loss. Journal of cellular biochemistry100, 960-969, doi:10.1002/jcb.21060 (2007).

25 Braun, T. P. et al. Cancer- and endotoxin-induced cachexia require intact glucocorticoid signaling in skeletal muscle. FASEB journal : official publication of the Federation of American Societies for Experimental Biology27, 3572-3582, doi:10.1096/fj.13-230375 (2013).

26 Lee, J. H. et al. Inhibited inositol monophosphatase and decreased myo-inositol concentration improve wasting in skeletal muscles. Clinical and translational medicine10, e251, doi:10.1002/ctm2.251 (2020).

27 Ma, Z., Zhong, Z., Zheng, Z., Shi, X. M. \& Zhang, W. Inhibition of glycogen synthase kinase-3beta attenuates glucocorticoid-induced suppression of myogenic differentiation in vitro. PloS one9, e105528, doi:10.1371/journal.pone.0105528 (2014). 
28 Abu-Baker, A. et al. Lithium chloride attenuates cell death in oculopharyngeal muscular dystrophy by perturbing Wnt/beta-catenin pathway. Cell death \& disease4, e821, doi:10.1038/cddis.2013.342 (2013).

29 Kim, A., Im, M., Gu, M. J. \& Ma, J. Y. Citrus unshiu peel extract alleviates cancer-induced weight loss in mice bearing CT-26 adenocarcinoma. Scientific reports6, 24214, doi:10.1038/srep24214 (2016).

30 Stambolic, V., Ruel, L. \& Woodgett, J. R. Lithium inhibits glycogen synthase kinase-3 activity and mimics wingless signalling in intact cells. Current biology : CB6, 1664-1668, doi:10.1016/s09609822(02)70790-2 (1996).

31 Gomes, M. D., Lecker, S. H., Jagoe, R. T., Navon, A. \& Goldberg, A. L. Atrogin-1, a muscle-specific F-box protein highly expressed during muscle atrophy. Proc Natl Acad Sci U S A98, 14440-14445, doi:10.1073/pnas.251541198 (2001).

32 Sandri, M. et al. Foxo transcription factors induce the atrophy-related ubiquitin ligase atrogin- 1 and cause skeletal muscle atrophy. Cel/117, 399-412, doi:10.1016/s0092-8674(04)00400-3 (2004).

33 Singh, N. et al. A safe lithium mimetic for bipolar disorder. Nat Commun4, 1332, doi:10.1038/ncomms2320 (2013).

34 Hung, Y. L. et al. Corylin protects LPS-induced sepsis and attenuates LPS-induced inflammatory response. Scientific reports7, 46299, doi:10.1038/srep46299 (2017).

35 Kumar, S. et al. Interleukin-1 alpha promotes tumor growth and cachexia in MCF-7 xenograft model of breast cancer. The American journal of pathology163, 2531-2541, doi:10.1016/s0002-9440(10)63608-5 (2003).

36 Narsale, A. A. \& Carson, J. A. Role of interleukin-6 in cachexia: therapeutic implications. Curr Opin Support Palliat Care8, 321-327, doi:10.1097/SPC.0000000000000091 (2014).

37 Hall, D. T., Ma, J. F., Marco, S. D. \& Gallouzi, I. E. Inducible nitric oxide synthase (iNOS) in muscle wasting syndrome, sarcopenia, and cachexia. Aging (Albany NY)3, 702-715, doi:10.18632/aging.100358 (2011).

38 Buck, M. \& Chojkier, M. Muscle wasting and dedifferentiation induced by oxidative stress in a murine model of cachexia is prevented by inhibitors of nitric oxide synthesis and antioxidants. EMBO J15, 17531765 (1996).

39 Hall, D. T. et al. The AMPK agonist 5-aminoimidazole-4-carboxamide ribonucleotide (AICAR), but not metformin, prevents inflammation-associated cachectic muscle wasting. EMBO molecular medicine10, doi:10.15252/emmm.201708307 (2018).

40 Tanaka, M., Miyazaki, H., Takeda, Y. \& Takeo, S. Detection of serum cytokine levels in experimental Loading [MathJax]/jax/output/CommonHTML/jax.js 
3835(93)90012-x (1993).

41 Evans, W. J. et al. Cachexia: a new definition. Clin Nutr27, 793-799, doi:10.1016/j.clnu.2008.06.013 (2008).

42 Strassmann, G., Fong, M., Kenney, J. S. \& Jacob, C. O. Evidence for the involvement of interleukin 6 in experimental cancer cachexia. The Journal of clinical investigation89, 1681-1684, doi:10.1172/JCl115767 (1992).

43 Strassmann, G. et al. Suramin interferes with interleukin-6 receptor binding in vitro and inhibits colon26-mediated experimental cancer cachexia in vivo. The Journal of clinical investigation92, 2152-2159, doi:10.1172/JCl116816 (1993).

44 Schakman, O. et al. Role of Akt/GSK-3beta/beta-catenin transduction pathway in the muscle antiatrophy action of insulin-like growth factor-I in glucocorticoid-treated rats. Endocrinology149, 3900-3908, doi:10.1210/en.2008-0439 (2008).

45 Schmidt, M., Poser, C. \& von Maltzahn, J. Wnt7a Counteracts Cancer Cachexia. Mol Ther Oncolytics16, 134-146, doi:10.1016/j.omto.2019.12.011 (2020).

46 Singh, N. et al. Effect of the Putative Lithium Mimetic Ebselen on Brain Myo-Inositol, Sleep, and Emotional Processing in Humans. Neuropsychopharmacology : official publication of the American College of Neuropsychopharmacology41, 1768-1778, doi:10.1038/npp.2015.343 (2016).

47 Liu, L. et al. MicroRNA-140 inhibits skeletal muscle glycolysis and atrophy in endotoxin-induced sepsis in mice via the WNT signaling pathway. American journal of physiology. Cell physiology317, C189-C199, doi:10.1152/ajpcell.00419.2018 (2019).

48 Dehoux, M. et al. IGF-I does not prevent myotube atrophy caused by proinflammatory cytokines despite activation of Akt/Foxo and GSK-3beta pathways and inhibition of atrogin-1 mRNA. Am J Physiol Endocrinol Metab292, E145-150, doi:10.1152/ajpendo.00085.2006 (2007).

49 Verhees, K. J. et al. Glycogen synthase kinase-3beta is required for the induction of skeletal muscle atrophy. American journal of physiology. Cell physiology301, C995-C1007, doi:10.1152/ajpcell.00520.2010 (2011).

50 van der Velden, J. L. et al. Inhibition of glycogen synthase kinase-3beta activity is sufficient to stimulate myogenic differentiation. American journal of physiology. Cell physiology290, C453-462, doi:10.1152/ajpcell.00068.2005 (2006).

51 Ragozzino, E. et al. 6-Bromoindirubin-3'-oxime intercepts GSK3 signaling to promote and enhance skeletal muscle differentiation affecting miR-206 expression in mice. Scientific reports 9,18091 , doi:10.1038/s41598-019-54574-4 (2019).

Loading [MathJax]/jax/output/CommonHTML/jax.js

Page $15 / 22$ 
52 Liu, L. et al. 6-Bromoindirubin-3'-oxime inhibits JAK/STAT3 signaling and induces apoptosis of human melanoma cells. Cancer research71, 3972-3979, doi:10.1158/0008-5472.CAN-10-3852 (2011).

53 Guadagnin, E., Mazala, D. \& Chen, Y. W. STAT3 in Skeletal Muscle Function and Disorders. Int J Mol Sci19, doi:10.3390/ijms19082265 (2018).

54 Qin, L. et al. A deep investigation into the adipogenesis mechanism: profile of microRNAs regulating adipogenesis by modulating the canonical Wnt/beta-catenin signaling pathway. BMC Genomics 11,320 , doi:10.1186/1471-2164-11-320 (2010).

55 Eldar-Finkelman, H., Schreyer, S. A., Shinohara, M. M., LeBoeuf, R. C. \& Krebs, E. G. Increased glycogen synthase kinase-3 activity in diabetes- and obesity-prone C57BL/6J mice. Diabetes48, 1662-1666, doi:10.2337/diabetes.48.8.1662 (1999).

56 Tomasin, R., Martin, A. \& Cominetti, M. R. Metastasis and cachexia: alongside in clinics, but not so in animal models. Journal of cachexia, sarcopenia and muscle10, 1183-1194, doi:10.1002/jcsm. 12475 (2019).

57 PV, S. et al. Effect of lithium administration on muscle and body weight loss in experimental cancer cachexia. European Journal of Internal Medicine19S, S1-S59 (2008).

58 Bertsch, S., Lang, C. H. \& Vary, T. C. Inhibition of glycogen synthase kinase 3[beta] activity with lithium in vitro attenuates sepsis-induced changes in muscle protein turnover. Shock35, 266-274, doi:10.1097/SHK.0b013e3181fd068c (2011).

59 Khasraw, M., Ashley, D., Wheeler, G. \& Berk, M. Using lithium as a neuroprotective agent in patients with cancer. BMC Med10, 131, doi:10.1186/1741-7015-10-131 (2012).

60 van der Werf, A., van Bokhorst, Q. N. E., de van der Schueren, M. A. E., Verheul, H. M. W. \& Langius, J. A. E. Cancer Cachexia: Identification by Clinical Assessment versus International Consensus Criteria in Patients with Metastatic Colorectal Cancer. Nutr Cancer70, 1322-1329, doi:10.1080/01635581.2018.1504092 (2018).

61 Argiles, J. M., Lopez-Soriano, F. J., Stemmler, B. \& Busquets, S. Therapeutic strategies against cancer cachexia. Eur J Trans/ Myol29, 7960, doi:10.4081/ejtm.2019.7960 (2019).

62 Alsady, M., Baumgarten, R., Deen, P. M. \& de Groot, T. Lithium in the Kidney: Friend and Foe? Journal of the American Society of Nephrology : JASN27, 1587-1595, doi:10.1681/ASN.2015080907 (2016).

63 Martinsson, L., Westman, J., Hallgren, J., Osby, U. \& Backlund, L. Lithium treatment and cancer incidence in bipolar disorder. Bipolar Disord1 8, 33-40, doi:10.1111/bdi.12361 (2016).

64 Zarse, K. et al. Low-dose lithium uptake promotes longevity in humans and metazoans. Eur J Nutr50, 011). 


\section{Figures}

\section{Figure 1}

A

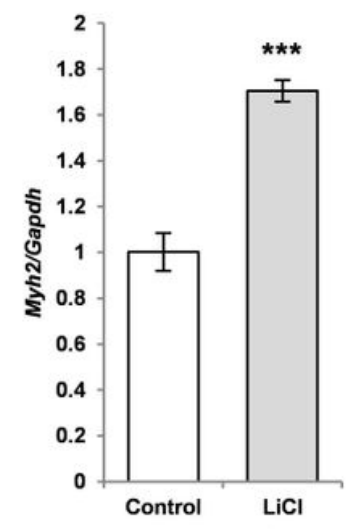

D

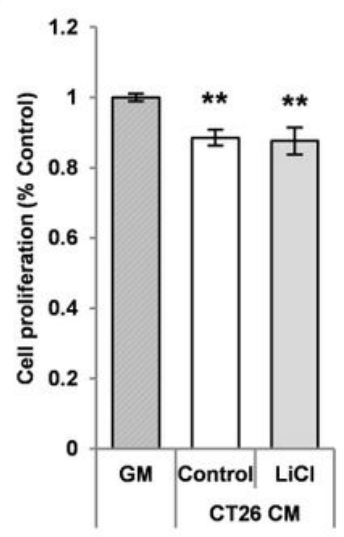

B

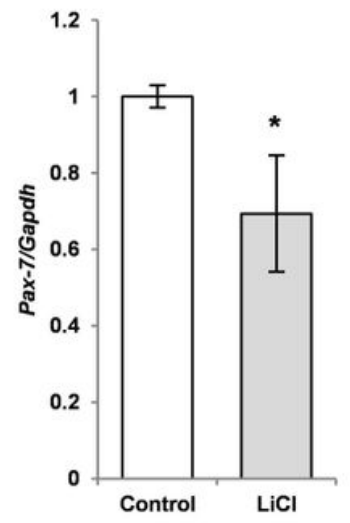

C

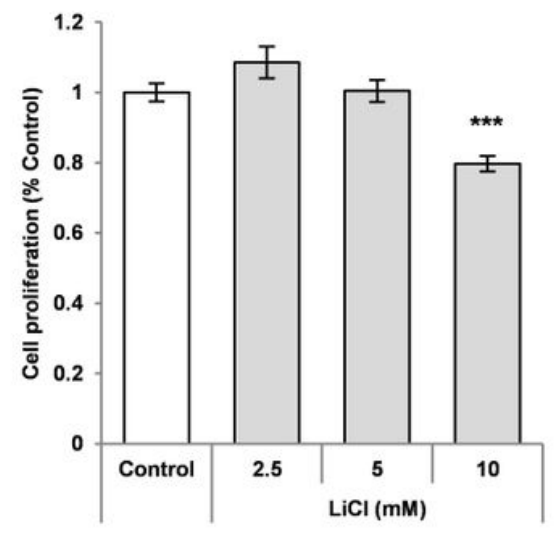

F

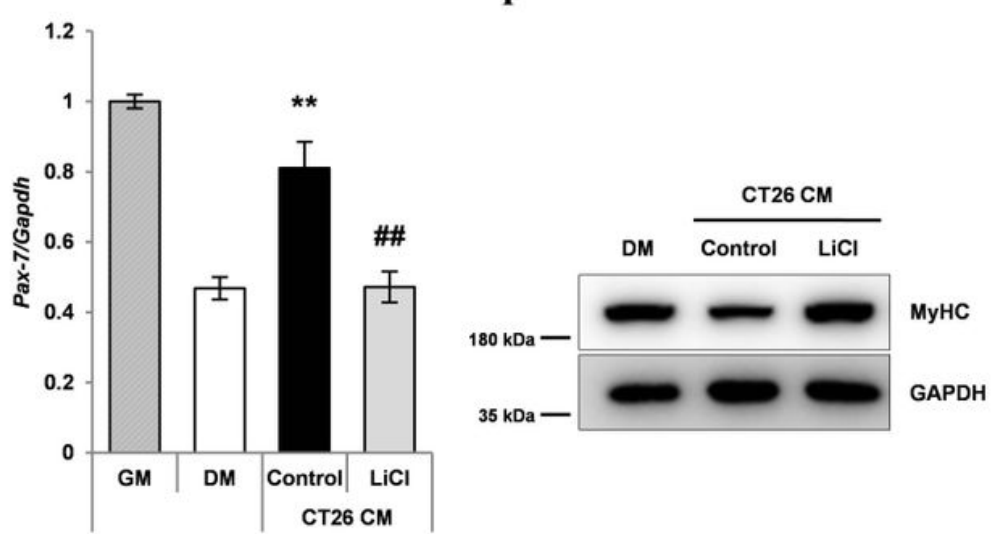

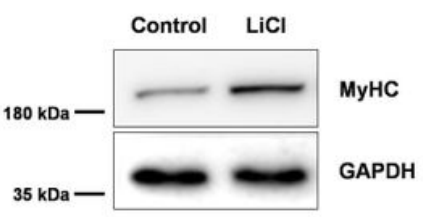

$\mathrm{LiCl}(\mathrm{mM})$

Figure 1

E

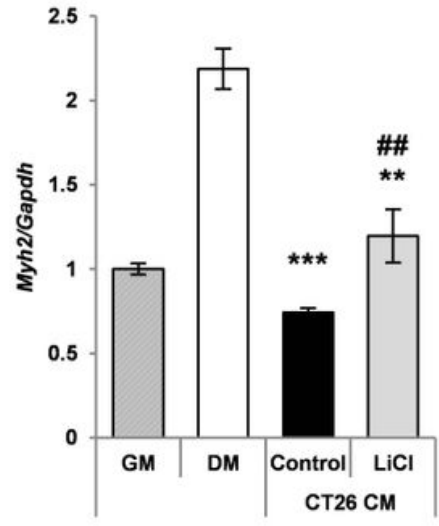




\section{Figure 2}

A

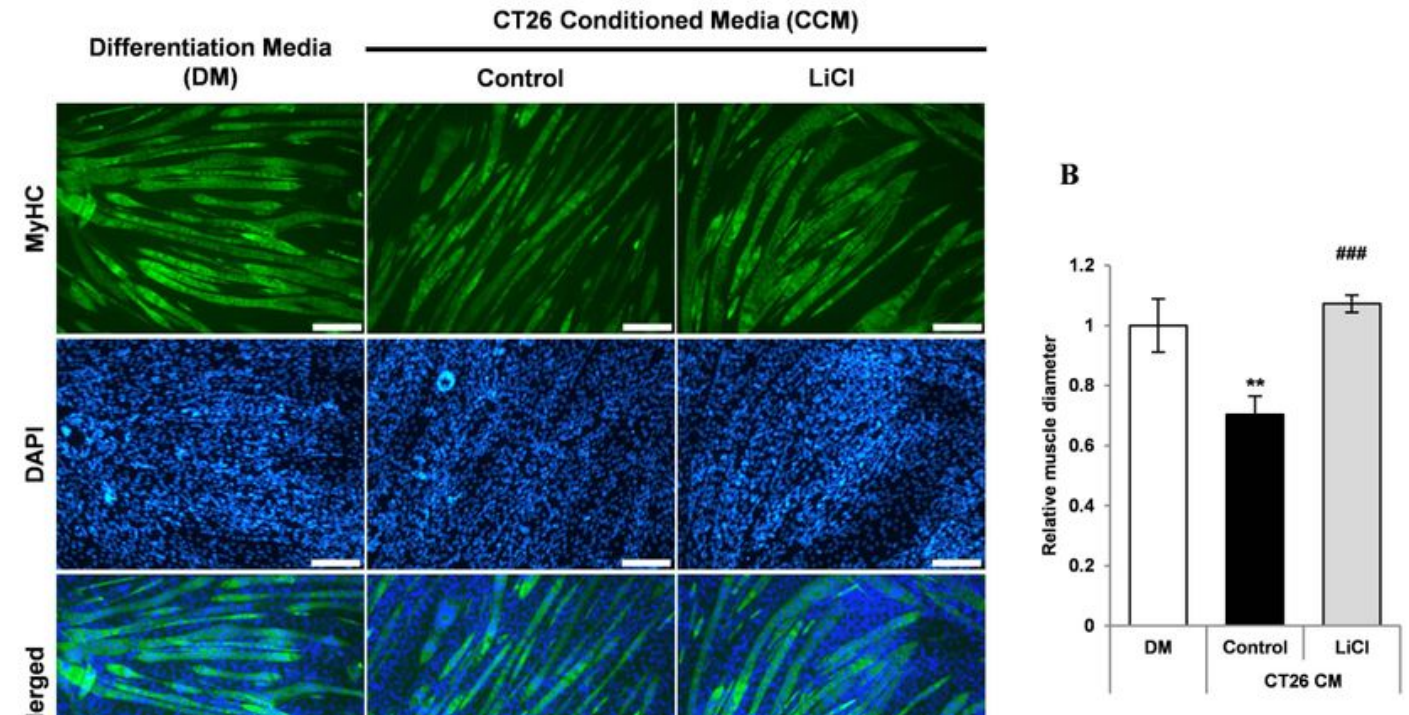

C
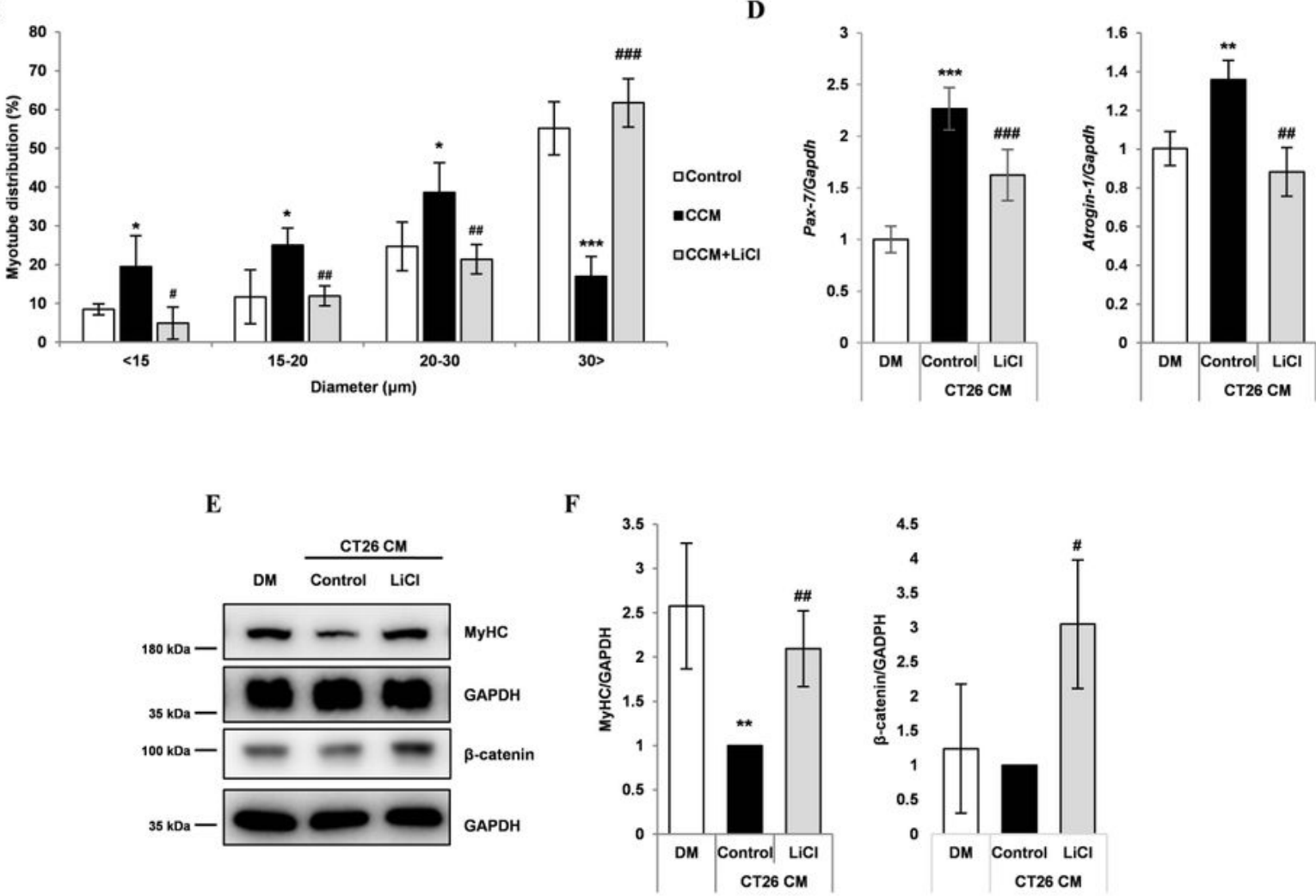

Figure 2

$\mathrm{LiCl}$ prevents CCM-mediated wasting in C2C12 myotubes. (A) Immunofluorescence staining for MyHC after $72 \mathrm{~h}$ culture as follows: 1) DM, 2) CCM, 3) CCM and $5 \mathrm{mM} \mathrm{LiCl.} \mathrm{DAPI} \mathrm{staining} \mathrm{was} \mathrm{used} \mathrm{to} \mathrm{visualize}$ cell nuclei. Scale bar=100 $\mu \mathrm{m}(\mathrm{n}=4)$. (B) Quantification of relative myotube diameter $(\mathrm{n}=4)$. (C) Frequency distribution of individual myotube diameters. (D) qPCR of Pax-7 and Atrogin-1 expression in myotubes 
$\mathrm{mM} \mathrm{LiCl}$ for $24 \mathrm{~h}(\mathrm{n}=3)$. (E) Western blot for MyHC and GAPDH in C2C12 myotubes after $72 \mathrm{~h}$ culture as follows: 1) DM, 2) CCM, 3) CCM and $5 \mathrm{mM} \mathrm{LiCl}(\mathrm{n}=4)$. Lower panel shows western blot for $\beta$-catenin and GAPDH in C2C12 myotubes after $24 \mathrm{~h}$ culture as follows: 1) DM, 2) CCM, 3) CCM and $5 \mathrm{mM} \mathrm{LiCl}(\mathrm{n}=3)$. (F) Quantification results of western blots for $\mathrm{MyHC}(n=4)$ and $\beta$-Catenin $(n=3)$. Significance compared to DM treatment was marked with $*(*=p-v a l u e<0.05, * *=p$-value $<0.01, * * *=p-v a l u e<0.001)$. Significance

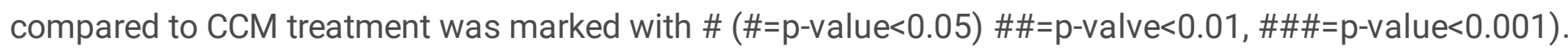

\section{Figure 3}

The lithium mimetic and IMPase inhibitor, ebselen, does not attenuate CCM-induced wasting in $\mathrm{C} 2 \mathrm{C} 12$ myotubes. (A) Immunofluorescence staining for MyHC after $72 \mathrm{~h}$ culture as follows: 1) DM, 2) CCM, 3) $\mathrm{CCM}$ and $5 \mathrm{mM} \mathrm{LiCl}, 4) \mathrm{CCM}$ and $10 \mu \mathrm{M}$ ebselen. DAPI staining was used to visualize cell nuclei. Scale bar $=100 \mu \mathrm{m}$. $(n=3)$. (B) Quantification of relative myotube diameter. $(n=3)$. (C) qPCR analysis for Atrogin1 after $24 \mathrm{~h}$ treatment ( $\mathrm{n}=3$ ). (D) qPCR analysis for myotube marker, Myh2, and myoblast marker, Pax-7, after 24 treatment $(n=3)$. Significance compared to DM was marked with * $(*=p-v a l u e<0.05, * *=p-$ value $<0.01, * * *=p$-value $<0.001)$. Significance compared to CCM treatment was marked with \# (\#=pvalue $<0.05, \# \#=p-v a l u e<0.01, \# \#=p-v a l u e<0.001)$.

\section{Figure 4}
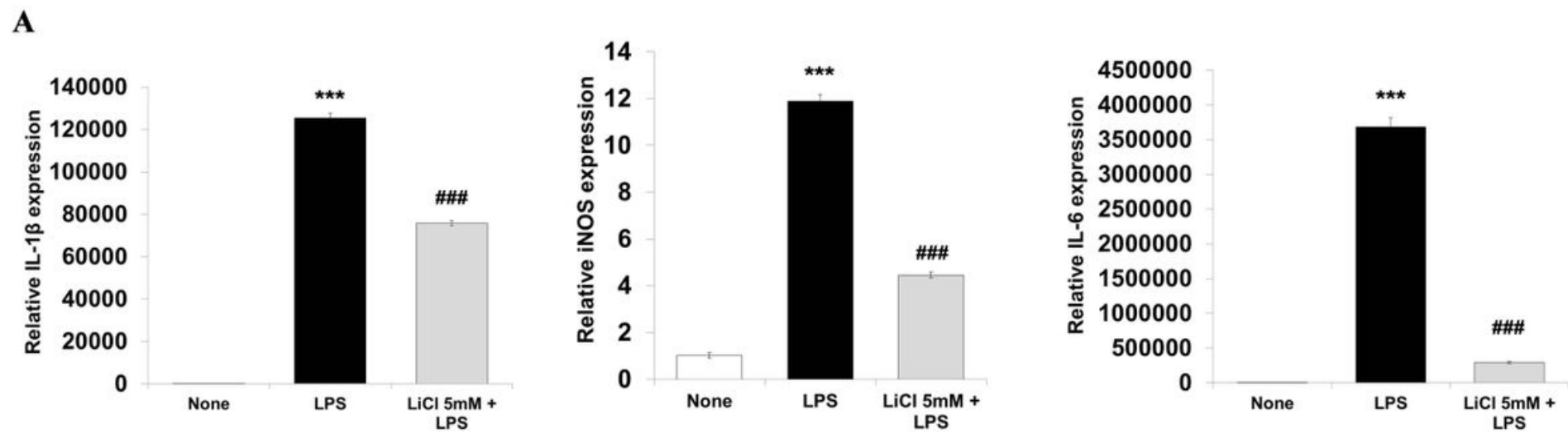

Figure 4

$\mathrm{LiCl}$ treatment blocks the LPS-induced upregulation of inflammatory cytokines from RAW264.7 macrophages. (A) qPCR analysis of IL-1 $\beta$, iNOS, and IL- 6 after treatment with $5 \mathrm{mM} \mathrm{LiCl}$ treatment for 24 $\mathrm{h}$, followed by $5 \mathrm{mM} \mathrm{LiCl}$ and $200 \mathrm{ng} / \mathrm{mL}$ LPS for an additional $24 \mathrm{~h}$. Significance compared to no treatment was marked with * $(* \star *=p-v a l u e<0.001)$. Significance compared to LPS treatment was marked with \# (\#\#\#=p-value<0.001). 
Figure 5

A

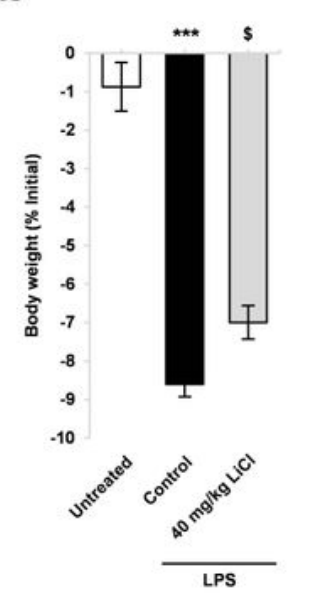

B

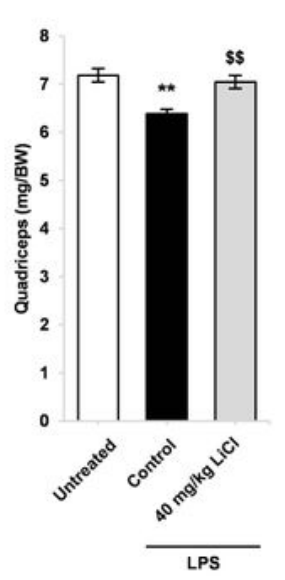

C
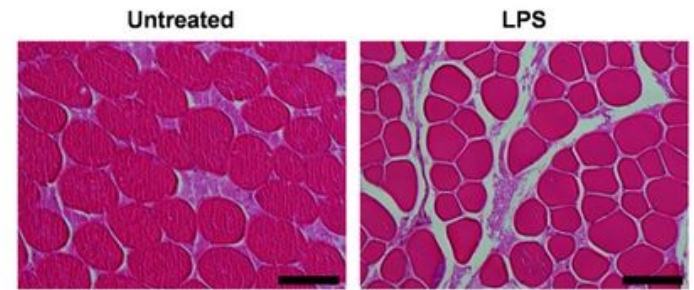

LPS $+40 \mathrm{mg} / \mathrm{kg}$ LiCI

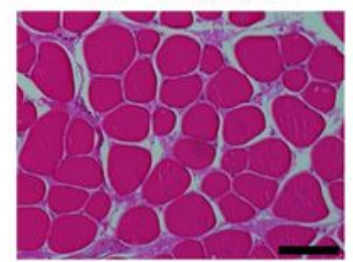

D

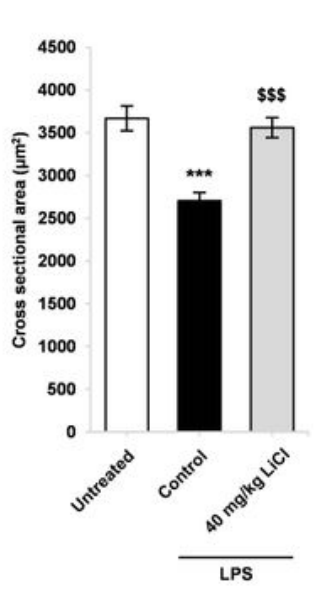

E

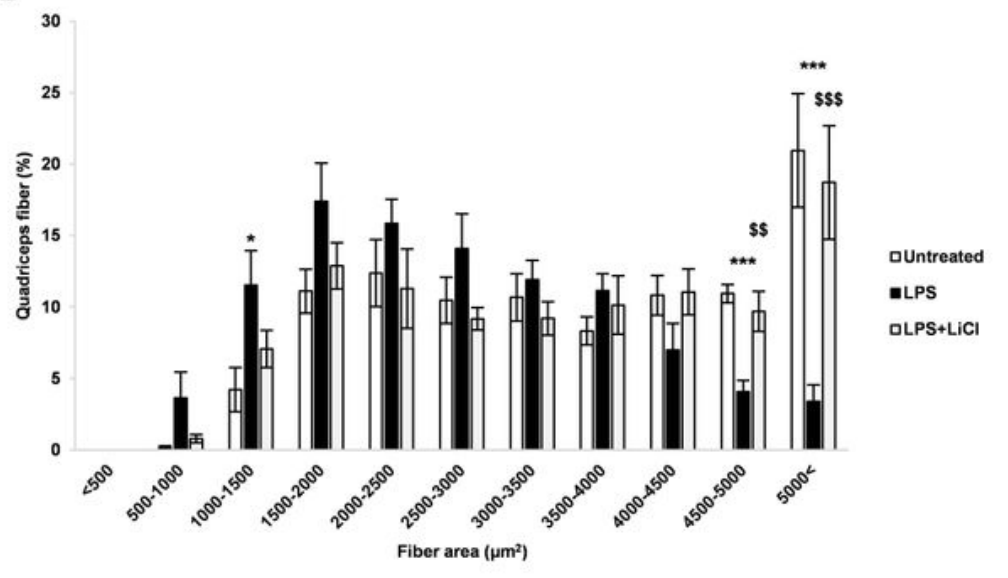

F
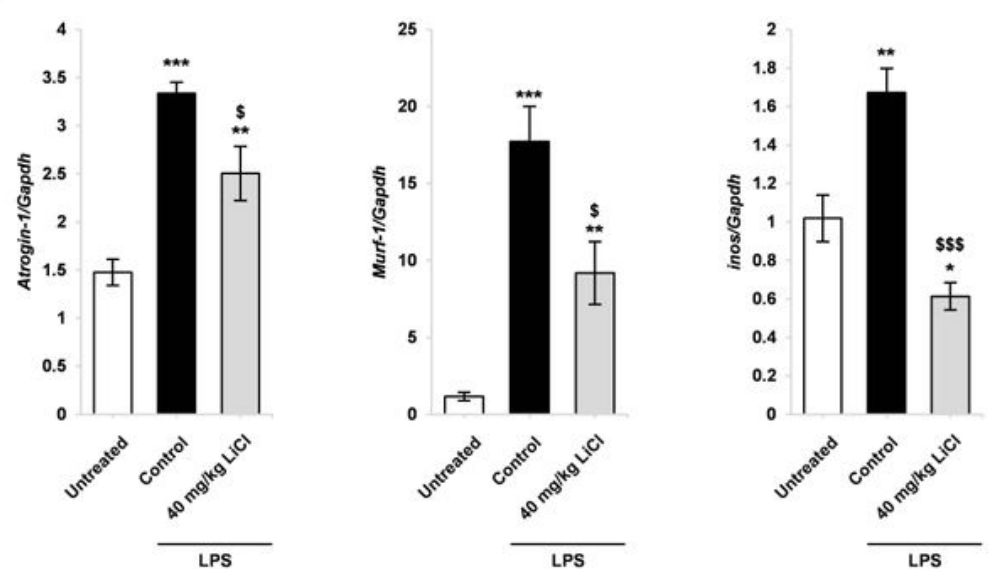

Figure 5

Therapeutic efficacy of LiCl for skeletal muscle wasting in a model of sepsis. Mice were treated as follows: 1) no treatment, 2) saline for $96 \mathrm{~h}$ followed by $1 \mathrm{mg} / \mathrm{kg} \mathrm{LPS}$, and 3) $40 \mathrm{mg} / \mathrm{kg} \mathrm{LiCl} \mathrm{for} 96 \mathrm{~h}$ followed by $1 \mathrm{mg} / \mathrm{kg}$ LPS. (A) Relative body weight change after $18 \mathrm{~h}(\mathrm{n}=7)$. (B) Quadriceps weight/body weight (mg/BW) ratio ( $n=6)$. (C) Representative H\&E stained images of the quadriceps (scale bar=100 Loading [MathJax]/jax/output/CommonHTML/jax.js $n$ the quadriceps $(n=5)$. (E) Frequency distribution of the 
cross sectional area in the quadriceps ( $n=5)$. (F) qPCR analysis of inos, Atrogin- 1 and Murf- 1 in the quadriceps $(n=5)$. Significant difference compared to untreated was marked with $*(*=p-v a l u e<0.05, * *=p-$ value $<0.01, * \star *=p$-value $<0.001$ ). Significant difference compared to saline plus LPS (control) was marked with $\$(\$=p-v a l u e<0.05$,

$$
=p-\text { value }<0.01
$$

$\$=p$-value $<0.001)$.

\section{Figure 6}

$\mathrm{LiCl}$ ameliorates muscle wasting in a mouse model of cancer cachexia. Mice were treated as follows: 1) no treatment, 2) transplantation with CT26 colon carcinoma cells, 3) transplantation with CT26 cells and treatment with $40 \mathrm{mg} / \mathrm{kg} \mathrm{LiCl}, 4)$ transplantation with $\mathrm{CT} 26$ cells and treatment with $80 \mathrm{mg} / \mathrm{kg} \mathrm{LiCl}$. (A) Body weight change $(n=5)$. (B) Time dependent growth of tumor volume $(n=5)$. (C) Dissected tumor mass. (D) Tumor free body weight. (E) Quadriceps and tibialis anterior muscle weight /body weight (mg/BW) ratio. (F) Gonadal adipose tissue mass. For (C-F) n=5 at 28 d post-transplantation. (G) Grip strength at $21 \mathrm{~d}$ post-transplantation $(n=5)$. (H) Representative H\&E stained images of the quadriceps (scale bar=100 $\mu \mathrm{m})$. (I) Average fiber cross sectional area in the quadriceps $(n=4)$. (J) Frequency distribution of the cross sectional area in the quadriceps $(n=4)$. Significant difference compared to saline was marked with $*\left(*=p-v a l u e<0.05,{ }^{* *}=p-\right.$ value $\left.<0.01, * * *=p-v a l u e<0.001\right)$. Significant difference compared

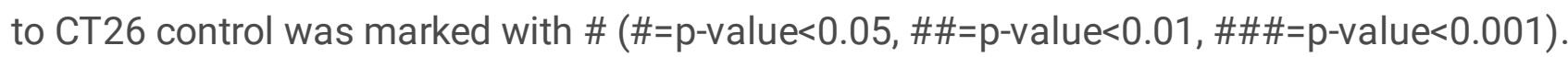

\section{Figure 7}

A

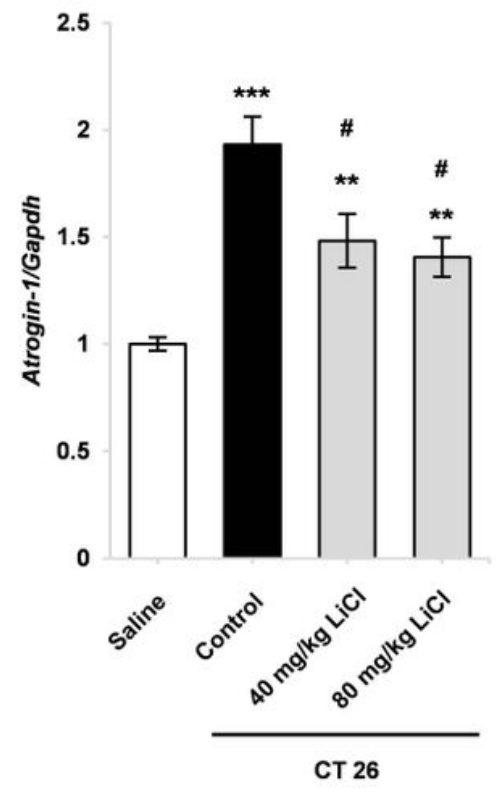

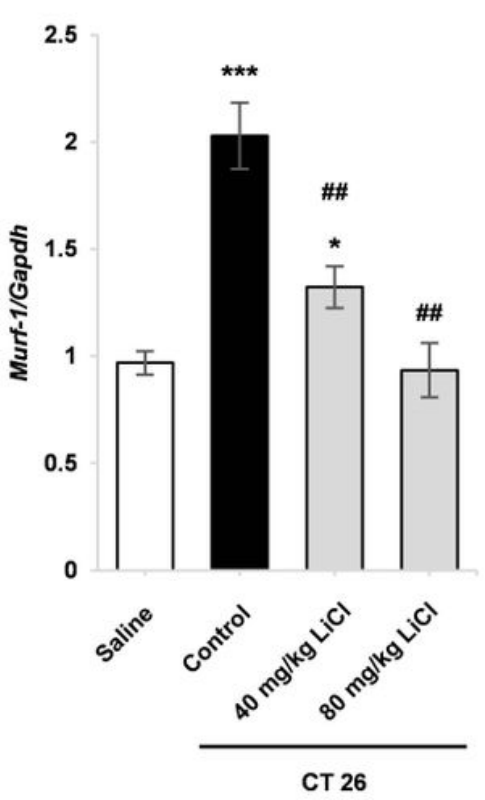

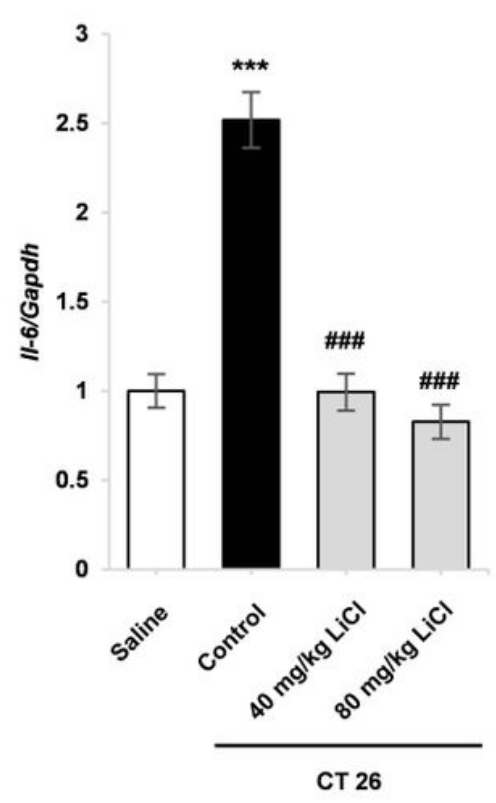


$\mathrm{LiCl}$ inhibited the upregulation of cachexia related genes in tumor bearing mice. qPCR analysis of Atrogin1 , Murf- 1 and II-6 in quadriceps muscle ( $n=4)$. 10 days after tumor inoculation, $40 \mathrm{mg} / \mathrm{kg}$ and $80 \mathrm{mg} / \mathrm{kg}$ of $\mathrm{LiCl}$ were administrated for additional 3 weeks and obtained quadriceps. Significant difference compared to saline was marked with * ${ }^{*}=p$-value $<0.05, * *=p$-value $<0.01, * * *=p$-value $\left.<0.001\right)$. Significant difference compared to CT26 control was marked with \# (\#=p-value $<0.05$, \#\#=p-value $<0.01$, \#\#\#=pvalue<0.001).

\section{Supplementary Files}

This is a list of supplementary files associated with this preprint. Click to download.

- SupplementaryFigures.pdf 